\title{
Fluorescent DNA hybridization probe preparation using amine modification and reactive dye coupling
}

\author{
W. Gregory Cox and Victoria L. Singer
}

BioTechniques 36:114-122 (January 2004)

\begin{abstract}
Fluorescent nucleic acid hybridization probes traditionally have been generated by enzymatic incorporation of dye-labeled nucleotides, even though incorporation efficiency is low and variable from dye to dye. Alternatively, 5-(3-aminoallyl)-2'-deoxyuridine 5'triphosphate (aa-dUTP) is enzymatically incorporated to generate amine-modified DNA, which is then chemically labeled with an amine-reactive fluorescent dye. We optimized this latter two-step approach for maximal hybridization signal brightness using DNA probes labeled to varying degrees with different fluorescent dyes. Reverse transcriptase and DNA polymerase I efficiently incorporated aa-dUTP into DNA, and adjusting the aa-dUTP:dTTP ratio controlled the degree of substitution. With cDNA probes hybridized to dot blots, probes having approximately eight dyes per 100 bases gave the best sensitivity, irrespective of the dye label. $\alpha$-Satellite probes generated by nick translation and hybridized to human chromosome spreads also showed that probes having approximately eight dyes per 100 bases provided the brightest overall signals. These data demonstrate that this labeling method generates highly sensitive DNA probes that are difficult to obtain by conventional direct incorporation approaches. The technique is inherently consistent and versatile by virtue of the efficient incorporation of primary amines and the reliable chemical labeling reaction.
\end{abstract}

\section{INTRODUCTION}

Nucleic acid hybridization probes traditionally are generated by enzymatic incorporation of labeled nucleotides. However, the use of fluorescently labeled nucleotides has an inherent limitation, since most enzymes incorporate dye-labeled nucleotides poorly (1-3). At best, typical enzymatic labeling reactions incorporate two to four dyemodified nucleotides per 100 bases (3-5). Labeling efficiency also varies significantly from label to label when modified nucleotides are used, making it difficult to compare signals obtained using probes labeled with different dyes or haptens (1-7). This has been particularly problematic for two-color microarray-based analyses, where $\mathrm{Cy}^{\mathrm{TM}} 3$ and Cy5 dye-labeled nucleotides are used for labeling $(8,9)$. Consequently, such hybridization assays must rely on comparisons of relative uptake to compare two differently labeled probes. Methods for increasing and controlling the degree of labeling (DOL), regardless of the label, can enhance the sensitivity of the probe and the strength of the assay. Since factors such as brightness, target specificity, duplex stability, and dye quenching can affect assay efficacy, monitoring hybridization signal brightness should ultimately optimize nucleic acid probes.

An alternative strategy to generating fluorescent DNA hybridization probes utilizes enzymatic incorporation of a nucleotide analog having an unobtrusive aliphatic primary amine group, which is subsequently labeled with an amine-reactive fluorescent dye. The two-step labeling method was first described for synthetic oligonucleotides $(10,11)$ and has proven to be useful for labeling enzymatically modified DNA as well. This two-step labeling approach commonly uses 5-(3-aminoallyl)-2'-deoxyuridine 5 -triphosphate (aa-dUTP) for enzymatic incorporation and circumvents the problems commonly associated with direct in- corporation of dye-labeled nucleotides (12). While the use of this approach is becoming widespread, optimization of the methodology has yet to be reported. In this work, single-stranded DNA (reverse transcription) and double-stranded DNA (nick translation) labeling protocols were optimized for hybridization signal brightness using dot blot and fluorescence in situ hybridization (FISH) assays for a variety of fluorescent dyes ranging in excitation wavelengths from the ultraviolet to the far-red.

\section{MATERIALS AND METHODS}

\section{Reverse Transcription}

Mouse $\beta$-actin RNA was generated using a MEGAScript ${ }^{\circledR}$ In Vitro Transcription Kit and pTRI $\beta$-actin plasmid (both from Ambion, Austin, TX, USA). cDNA was generated with SuperScript ${ }^{\mathrm{TM}}$ II reverse transcriptase (Invitrogen, Carlsbad, CA, USA), per 
the manufacturer's protocol, with 5 $\mu \mathrm{M}$ actin primer $\left(5^{\prime}\right.$-dCTAGACTTCGAGCAGGAGATGG-3'), $0.5 \mathrm{mM}$ each of dATP, dGTP, and dCTP, and varying ratios of aa-dUTP (Molecular Probes, Eugene, OR, USA) and dTTP. Afterwards, the nucleic acids were denatured at $95^{\circ} \mathrm{C}$ for $5 \mathrm{~min}$, and the template RNA was degraded with $\mathrm{NaOH}$ (0.3 M final concentration, 15 $\min$ at $\left.65^{\circ} \mathrm{C}\right)$. The reaction was then neutralized with $\mathrm{HCl}(0.3 \mathrm{M}$ final concentration) and buffered with Tris$\mathrm{HCl}$ buffer (0.1 M final concentration, $\mathrm{pH}$ 7.0). The cDNA was purified using the QIAquick ${ }^{\circledR}$ PCR Purification Kit (Qiagen, Valencia, CA, USA) per the manufacturer's protocol, except that $75 \%$ ethanol washes were used and the DNA was eluted in water or $1 \mathrm{mM}$ Tris-HCl buffer, $\mathrm{pH}$ 8.5. The DNA was precipitated with the addition of 0.1 volume of $3 \mathrm{M}$ sodium acetate, $\mathrm{pH}$ 5.2, and 2 volumes of absolute ethanol.

\section{Nick Translation}

Nick translation was performed following standard procedures (7) using chromosome $17 \alpha$-satellite probe DNA, p17H8 (13). Briefly, $1 \mu \mathrm{g}$ of p17H8 DNA was incubated in a total volume of $50 \mu \mathrm{L}$ nick translation buffer [50 mM Tris- $\mathrm{HCl}, 5 \mathrm{mM} \mathrm{MgCl}_{2}, 10$ $\mathrm{mM}$ dithiothreitol (DTT), $0.05 \mathrm{mg} / \mathrm{mL}$ bovine serum albumin (BSA), $\mathrm{pH} 7.8$ ] with $40 \mu \mathrm{M}$ each of dATP, dGTP, and dCTP, varying aa-dUTP:dTTP ratios, 15 U DNA polymerase I (Promega, Madison, WI, USA), and approximately 10 Kunitz units of DNase I. The DNase I concentration was optimized to generate an average fragment length of 250-500 bp. The reaction was incubated at $15^{\circ} \mathrm{C}$ for $2 \mathrm{~h}$ and then purified as described above.

\section{Labeling Amine-Modified DNA with Amine-Reactive Dyes}

Amine-modified DNA was resuspended in water $(0.2 \mu \mathrm{g} / \mu \mathrm{L})$, denatured at $95^{\circ} \mathrm{C}$ for $5 \mathrm{~min}$, snap-cooled on ice, and then centrifuged at $12,000 \mathrm{rpm}$ for $5 \mathrm{~min}$. Succinimidyl ester dyes (Molecular Probes) were dissolved in dimethyl sulfoxide (DMSO) or dimethyl formamide (DMF) to final concentrations of $20 \mu \mathrm{g} / \mu \mathrm{L}$. Labeling of $1 \mu \mathrm{g}$ of amine-modified DNA (0.2 $\mu \mathrm{g} / \mu \mathrm{L})$ was performed with $0.1 \mathrm{M}$ sodium bicarbonate, $\mathrm{pH} 8.5$, and $40 \mu \mathrm{g}$ of freshly dissolved reactive dye $(2 \mu \mathrm{L})$ in a total volume of $10 \mu \mathrm{L}$ for $1 \mathrm{~h}$ at room temperature and protected from the light. Afterwards, $90 \mu \mathrm{L}$ of nucleasefree water was added to the reaction, and the labeled DNA was purified as described above and eluted in $10 \mathrm{mM}$ Tris-HCl, $\mathrm{pH}$ 8.5.

\section{Determination of Degree of Labeling}

Absorption measurements were performed in 96-well, UV-transparent, flat-bottomed plates $\left(\right.$ Costar $^{\circledR} \mathrm{UV}$ plates; Corning Life Sciences, Acton, MA, USA) on the entire sample of $185 \mu \mathrm{L}$, which was determined to have a pathlength of $0.5 \mathrm{~cm}$. Absorption measurements at $260 \mathrm{~nm}$ and the dye absorption wavelength maximum for each dye were obtained using a HTS 7000 ${ }^{\mathrm{TM}}$ Bio Assay Reader spectrophotometer (PerkinElmer, Wellesley, MA, USA) with appropriate filters (Omega Optical, Brattleboro, VT, USA) or a SpectroMax ${ }^{\circledR}$ Plus spectrophotometer (Molecular Devices, Sunnyvale, CA, USA). The DOL of the labeled DNA, in number of dyes per 100 bases, was calculated using the Beer-Lambert law (see Table 2).

\section{Dot Blot Hybridization}

Mouse $\beta$-actin DNA was generated by PCR using the pTRI $\beta$-actin cDNA plasmid as a template and the actin primer oligonucleotides $\left(5^{\prime}\right.$-dGTGACACTATAGAATACACGG-3', 5'-dCTAGACTTCGAGCAGGAGATGG-3'). A dilution series of the resulting actin DNA, ranging from 25 ng to $24 \mathrm{pg}$ per sample, and $25 \mathrm{ng}$ of $\phi X 174$ DNA as a negative control were denatured and dot blotted onto nylon membrane per the manufacturer's guidelines (Bio-Dot ${ }^{\circledR}$ and Zeta-Probe ${ }^{\circledR}$ membrane; both from Bio-Rad Laboratories, Hercules, CA, USA). Blots were blocked in Solution A [6× SSPE (0.9 M NaCl, $60 \mathrm{mM} \mathrm{NaH} \mathrm{PO}_{4}, 6$ mM EDTA, pH 7.4), 5× Denhardt's solution (Sigma, St. Louis, MO, USA), $0.1 \mathrm{mg} / \mathrm{mL}$ sheared, denatured herring sperm DNA, $0.5 \%$ sodium dodecyl sulfate (SDS), $50 \%$ formamide] for $2 \mathrm{~h}$ at 
$42^{\circ} \mathrm{C}$ and then hybridized with $1 \mu \mathrm{g} / \mathrm{mL}$ labeled probe in Solution B (Solution A without Denhardt's solution) overnight at $42^{\circ} \mathrm{C}$. After hybridization, blots were washed twice in $2 \times \mathrm{SSC}(15 \mathrm{mM} \mathrm{NaCl}$, $1.5 \mathrm{mM}$ sodium citrate, $\mathrm{pH} 7.0), 0.1 \%$ SDS at room temperature, and then in $0.1 \times \mathrm{SSC}, 0.1 \% \mathrm{SDS}$, at $65^{\circ} \mathrm{C}$ for 15 min with agitation.

\section{Dot Blot Signal Analysis}

Imaging was performed using a xenon arc-lamp- or laser-based gel imaging system (Arthur imager; PerkinElmer, or FLA-3000G imager; FUJI Photo Film, Tokyo, Japan). The instrument settings were normalized for each dye such that the exposure time chosen for further analysis was the longest exposure that did not produce pixel saturation, which was typically $1-5 \mathrm{~s}$, and was kept constant for the series of same dye-labeled probes. Hybridization signals were defined by the average of the pixel intensities within the defined dot area minus the average background determined at the negative control spot of $\phi X 174$ DNA. Three probe sets were hybridized separately, and the signals were averaged for each dye.

\section{Fluorescence In Situ Hybridization}

Nick-translated and labeled chromosome $17 \alpha$-satellite probe (13) were used for FISH analysis. Routine procedures were used to produce metaphase chromosome spreads from phytohemagglutinin-stimulated normal human peripheral blood lymphocyte cultures. Slides were aged in $2 \times \mathrm{SSC}$, $0.5 \%$ Nonidet $^{\circledR} \mathrm{P}-40$ (NP40), $\mathrm{pH} 7.0$, at $37^{\circ} \mathrm{C}$ for $30 \mathrm{~min}$, dehydrated through an ethanol series $(70 \%, 80 \%, 95 \%)$ at room temperature for $2 \mathrm{~min}$ each, airdried, and stored at $-20^{\circ} \mathrm{C}$. For hybridization, slides were denatured in $70 \%$ formamide, $2 \times \mathrm{SSC}, \mathrm{pH} 7.0$, at $72^{\circ} \mathrm{C}$ for $2 \mathrm{~min}$, dehydrated through a $-20^{\circ} \mathrm{C}$ ethanol series $(70 \%, 80 \%, 95 \%)$ for 2 min each, and air-dried. Probe DNA in $65 \%$ formamide, $2 \times \mathrm{SSC}$ at a final concentration of $1 \mathrm{ng} / \mu \mathrm{L}$ with $10 \mu \mathrm{g}$ of sheared, denatured herring sperm DNA was denatured at $72^{\circ} \mathrm{C}$ for 5 min, snapcooled on ice, and applied to the slide under a glass coverslip. Hybridization was carried out overnight at $37^{\circ} \mathrm{C}$ in a humid chamber. Afterwards, the slides were soaked in $2 \times \mathrm{SSC}$ to remove the coverslips, equilibrated in $0.4 \times \mathrm{SSC}$ at room temperature, placed in $0.4 \times$ $\mathrm{SSC}$ at $72^{\circ} \mathrm{C}$ for $5 \mathrm{~min}$, and followed by phosphate-buffered saline (PBS) at room temperature. DNA was counterstained with $30 \mathrm{nM}$ DAPI (Molecular Probes), and the slides were mounted in $50 \%$ glycerol/PBS.

\section{FISH Signal Analysis}

Imaging was performed with a standard fluorescence microscope (Nikon, Melville, NY, USA) using a $60 \times$ oil immersion objective, a mercury arc-lamp (Nikon), appropriate bandpass filter sets (Omega Optical), a cooled chargecoupled device (CCD) camera (Princeton Instruments, Trenton, NJ, USA), and MetaMorph ${ }^{\circledR}$ software (Universal Imaging, Downington, PA, USA). The exposure time used was kept constant for the series of same dye-labeled probes and was the longest exposure that could be achieved with the brightest signal without pixel saturation. Typical exposure times were 20-50 ms for dyes with visible light emission and 5-15 s for dyes with far-red emission. FISH signal intensities were defined by the average of the pixel intensities within the defined spot area minus the average background determined at the periphery of the signal. For each probe, 18 signals were analyzed, and the results were averaged.

\section{RESULTS}

\section{Optimization of the Labeling Methodology}

The general labeling method was optimized first, both to determine how to achieve the highest possible labeling levels and to develop a procedure that would allow the labeling level to be controlled and predictable. The efficiency of the labeling method was judged by the DOL, or the number of dyes coupled to the DNA, determined using absorption spectroscopy. The Alexa Fluor ${ }^{\circledR} 488$ dye (Molecular Probes) was used to optimize the basic labeling method for cDNA, and the method was then validated using other dyes and other enzymatic incorpo- ration methods (i.e., nick translation). Different aspects of the basic labeling method were evaluated by the DOL obtained from labeling amine-modified cDNA with Alexa Fluor 488 succinimidyl ester dye. This cDNA was generated by reverse transcription in the presence of a 1:1 ratio of aa-dUTP:dTTP and was used first to determine the amount of reactive dye required to label $1 \mu \mathrm{g}$ of amine-modified cDNA in $1 \mathrm{~h}$. The DOL of the labeled cDNA did not increase using more than $30 \mu \mathrm{g}$ of reactive dye per reaction, but gave a lower DOL with lower amounts of reactive dye. Since the DOL did not increase, these results indicated that $30 \mu \mathrm{g}$ of reactive dye per reaction would be sufficient for labeling $1 \mu \mathrm{g}$ of amine-modified cDNA to saturation. Noting that the reactivity of these dye compounds can vary from batch to batch and over time due to the labile, moisture-sensitive nature of the succinimidyl ester group, $40 \mu \mathrm{g}$ of reactive dye were used per reaction for the remainder of the study to account for any variance in dye reactivity. Labeling efficiency was examined at 60, 90, and $120 \mathrm{~min}$, and the DOL did not increase significantly after $1 \mathrm{~h}$ of incubation with the reactive dye. The labeling buffers sodium bicarbonate and sodium borate were compared at $\mathrm{pH} 8.5$ and a concentration of $0.1 \mathrm{M}$. In these tests, cDNA synthesis was performed with varying ratios of aa-dUTP:dTTP to assess the fidelity of the labeling reaction. Labeling reactions performed in sodium bicarbonate buffer resulted in DOLs that increased significantly with increasing aa-dUTP: dTTP ratios. In contrast, labeling reactions with sodium borate showed only a slight increase in DOL with increasing aa-dUTP:dTTP ratio. Lower concentrations of both buffers gave lower DOLs and thus, were less efficient. Using these standard parameters (see Note Added in Proof), up to $5 \mu \mathrm{g}$ of cDNA could be labeled efficiently without a significant change in DOL. In addition, the labeling efficiency benefited from the presence of $20 \%$ (v/v) organic solvent, either DMSO or DMF, which was used to dissolve the reactive dye. While most reactive dyes tested performed well with DMSO or DMF, Pacific Blue and Alexa Fluor 350 dyes performed better with DMF. Also, heat denaturation of the amine-modified double-stranded DNA produced by nick 
Table 1. Fluorescent Dye Characteristics

\begin{tabular}{|c|c|c|c|}
\hline Fluorophore & $\begin{array}{c}\mathrm{Ex} / \mathrm{Em} \\
(\mathrm{nm})\end{array}$ & CF & $\begin{array}{c}\varepsilon \\
\left(\mathbf{c m}^{-1} \mathbf{M}^{-1}\right)\end{array}$ \\
\hline Alexa Fluor 350 & $345 / 440$ & 0.25 & 18,400 \\
\hline Pacific Blue & $410 / 455$ & 0.15 & 36,000 \\
\hline Alexa Fluor 488 & $492 / 520$ & 0.3 & 62,000 \\
\hline Alexa Fluor 532 & $525 / 550$ & 0.24 & 82,300 \\
\hline Alexa Fluor 546 & $555 / 570$ & 0.21 & 104,000 \\
\hline Alexa Fluor 594 & $588 / 615$ & 0.43 & 80,400 \\
\hline Alexa Fluor 660 & $660 / 690$ & 0 & 107,000 \\
\hline Alexa Fluor 680 & $680 / 700$ & 0 & 164,000 \\
\hline \multicolumn{4}{|c|}{$\begin{array}{l}\text { Ex, excitation maxima; Em, emission maxima; CF, correction factor } \\
\varepsilon \text {, molar extinction coefficient for the dye. } \\
\mathrm{CF} \text { is a measure of the contribution of the dye to the } 260 \mathrm{~nm} \text { absor- } \\
\text { bance of the conjugate, since most dyes absorb light at } 260 \mathrm{~nm} \text { as well } \\
\text { as at their excitation maximum, and is determined by the ratio of the } \\
\text { dye absorbance at } 260 \mathrm{~nm} \text { to the dye absorbance at its maximal absor- } \\
\text { bance wavelength. }\end{array}$} \\
\hline
\end{tabular}

of varying aa-dUTP: dTTP ratios in order to generate series of probes of varying DOL. The DOL of the probes correlated well with changes in aa-dUTP:dTTP ratio, regardless of the labeling dye chosen, and reached a maximum at an aadUTP:dTTP ratio of 3:1 (Table 2). Figure 1 shows a typical dot blot series hybridized with Alexa Fluor 594 dye-labeled cDNA probes. Hybridization signals showed a fluorescence response translation prior to dye coupling improved the DOL by approximately $10 \%$. This finding indicated that labeling is more efficient when the DNA is singlestranded and lacks secondary structure.

\section{Optimization of cDNA Labeling}

The efficacy of a hybridization probe should be judged by its hybridization signal intensity since the DOL reflects labeling efficiency but provides no indication as to hybrid stability or fluorescence output. Thus, signal brightness in dot blot hybridization assays was used to evaluate the cDNA probes and determine the optimal DOL, and thus the optimal aa-dUTP:dTTP ratio. cDNA probes were synthesized in the presence proportional to increasing amount of target DNA (Figure 2). Probes with a DOL of eight dyes per 100 bases on average had the best overall sensitivity, regardless of the dye label chosen, and reproducibly detected as little as $200 \mathrm{pg}$ of target DNA. Probes with a DOL of 10-10.8 dyes per 100 bases on average consistently had poor sensitivity, presumably due to unstable hybridization of the overlabeled probe and/or fluorescence quenching.

\section{Optimization of Double-Stranded DNA Labeling}

In similar fashion to the cDNA probe optimization, nick translation for double-stranded DNA probe synthesis was

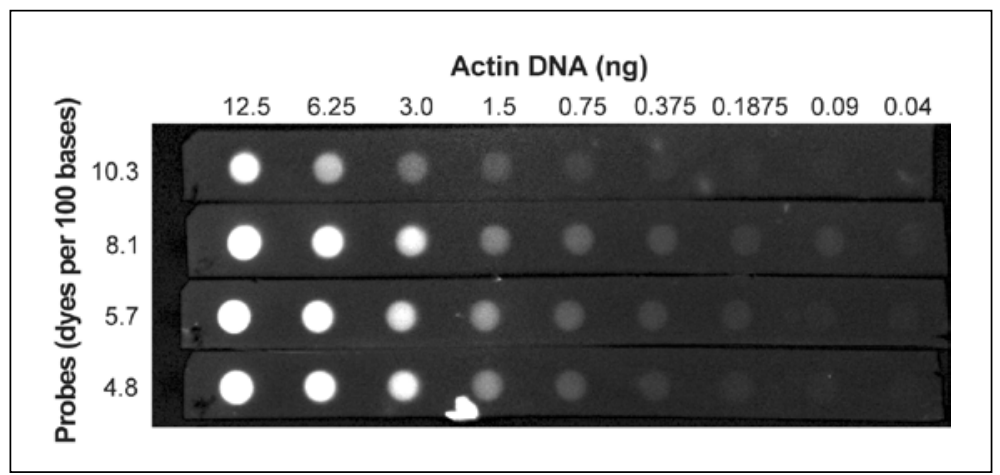

Figure 1. Actin dot blot hybridization with Alexa Fluor 594 dye-labeled cDNA probes. Imaging and analysis was performed using a xenon arc-lamp-based gel imaging system with $590 \pm 10 \mathrm{~nm}$ excitation and $620 \pm 10 \mathrm{~nm}$ emission filters and a 10 -s exposure time. The integrated fluorescence intensity of each hybridization signal was measured and compared relative to the degree of labeling (DOL) of the probe. Similar studies were performed with each of the dyes used for labeling. 
Table 2. Optimization of cDNA Labeling Using Actin cDNA Probes

\begin{tabular}{|c|c|c|c|c|c|c|c|}
\hline \multicolumn{2}{|c|}{ Dye Label } & \multirow{2}{*}{$\begin{array}{c}\begin{array}{c}\text { Alexa } \\
\text { Fluor } 488\end{array} \\
\text { DOL }\end{array}$} & \multirow{2}{*}{$\begin{array}{c}\begin{array}{c}\text { Alexa } \\
\text { Fluor } 532\end{array} \\
\text { DOL }\end{array}$} & \multirow{2}{*}{$\begin{array}{c}\begin{array}{c}\text { Alexa } \\
\text { Fluor } 546\end{array} \\
\text { DOL }\end{array}$} & \multirow{2}{*}{$\begin{array}{c}\begin{array}{c}\text { Alexa } \\
\text { Fluor } 594\end{array} \\
\text { DOL }\end{array}$} & \multirow{2}{*}{$\begin{array}{c}\begin{array}{c}\text { Alexa } \\
\text { Fluor } 660\end{array} \\
\text { DOL }\end{array}$} & \multirow{2}{*}{$\begin{array}{c}\begin{array}{c}\text { Alexa } \\
\text { Fluor } 680\end{array} \\
\text { DOL }\end{array}$} \\
\hline ratio & aa-dUTP:dTTP & & & & & & \\
\hline $2: 1$ & $300 \mu \mathrm{M}: 150 \mu \mathrm{M}$ & 8.3 & 8.2 & 8.3 & 8.1 & 8.3 & 8.0 \\
\hline $1: 1$ & $225 \mu \mathrm{M}: 225 \mu \mathrm{M}$ & 5.6 & 5.6 & 5.6 & 5.7 & 5.6 & 5.6 \\
\hline \multicolumn{8}{|c|}{ 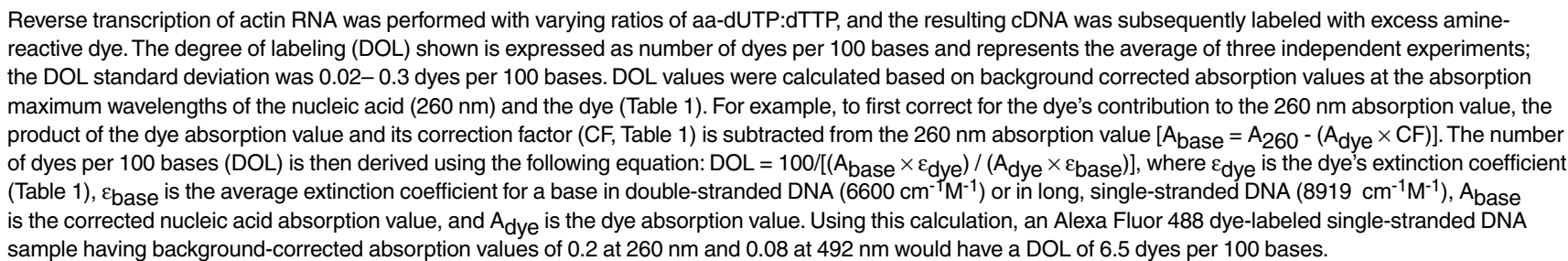 } \\
\hline
\end{tabular}
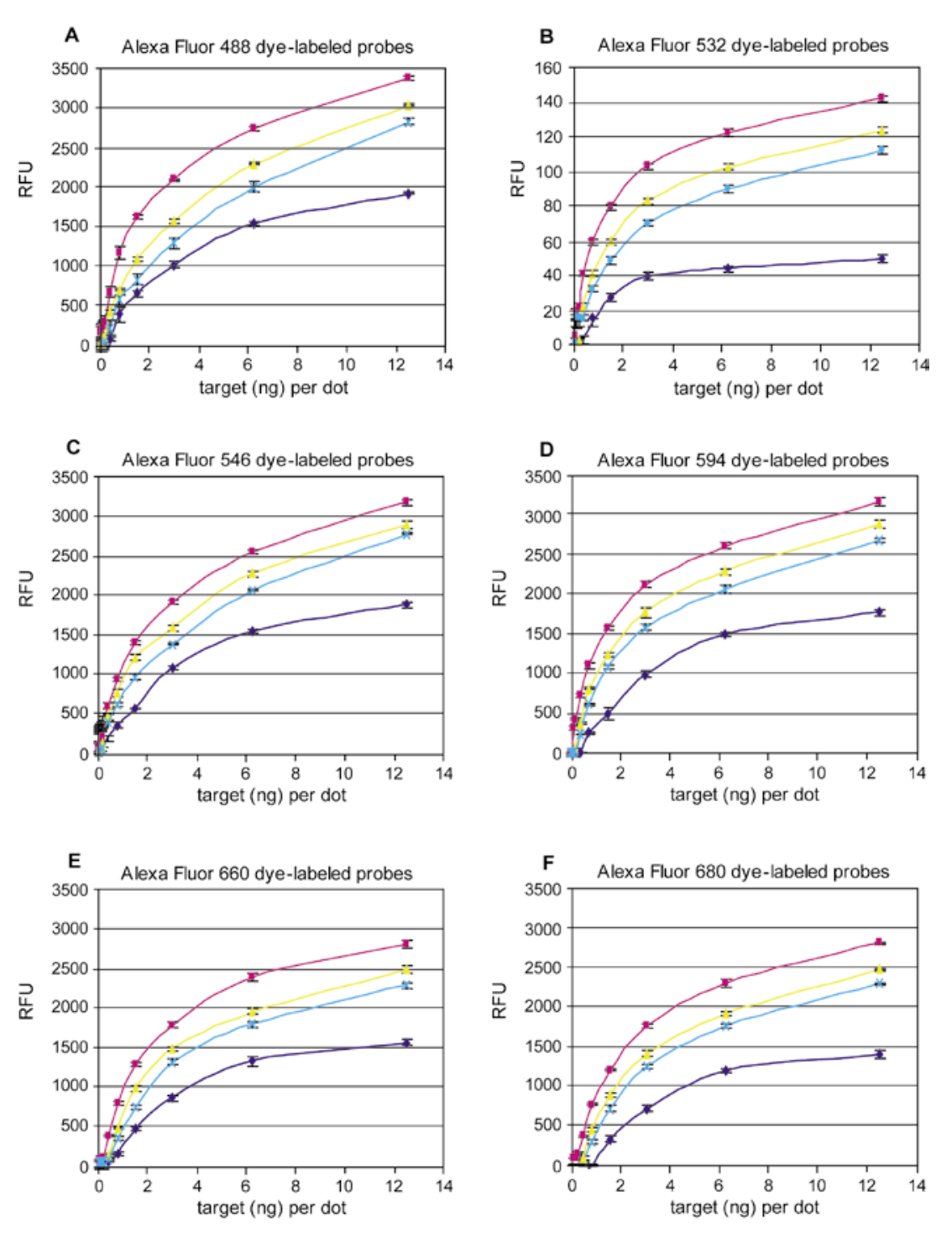

optimized based upon the best signal achieved in FISH assays. Chromosome $17 \alpha$-satellite DNA plasmid was nick translated in the presence of varying aadUTP:dTTP ratios to generate a series of probes of varying DOL. The DOL of the probes correlated with changes in aa-dUTP:dTTP ratio, regardless of the labeling dye used, and reached a maximum at an aa-dUTP:dTTP ratio of 9:1 (Table 3). Figure 3 shows typical hybridization signals obtained with Alexa Fluor 594 dye-labeled probes of three different DOLs. The brightest signals were obtained with probes having an average of eight dyes per 100 bases, regardless of the dye label chosen (Figure 4), provided by an aa-dUTP:dTTP

Figure 2. Image analysis of dot blot hybridizations. The integrated fluorescence intensity of dot blot hybridization signals were measured and compared relative to the degree of labeling (DOL) of the probe. Actin cDNA probes of 8.0-8.3 dyes per 100 bases gave the best overall sensitivity, regardless of the dye label chosen. Probes of $10-10.8$ dyes per 100 bases consistently gave poor signals. Signal intensities obtained using of Alexa Fluor 532 dye appear to be lower than those with other dyes; this is an artifact of the instrument used for imaging (FLA-3000G Imager), which had a suboptimally matched emission filter $(580 \mathrm{~nm})$ to the emission spectra of the dye and is not indicative of an actual difference in intensity between this dye and the spectrally similar Alexa Fluor 546 dye. The magenta-colored line corresponds to DOLs of 8.0-8.3; the yellow-colored line corresponds to DOLs of 5.6-5.7; the light blue-colored line corresponds to DOLs of 4.8-5.0; and the dark bluecolored line corresponds to DOLs of 10.0-10.8. $\mathrm{RFU}$, relative fluorescence units. 
ratio of $6: 1$ for nick translation. The brightness of the hybridization signals was observed to increase proportionally with increasing DOL; above a value of 8.3 , reached with an aa-dUTP:dTTP ratio of 6 , hybridization signals declined sharply presumably due to poor probetarget stability and/or fluorescence quenching of the overlabeled probe. No attempts were made to adjust the hybridization stringency for the more densely labeled probes.

\section{DISCUSSION}

The sensitivity of a fluorescent nucleic acid probe of any given length is determined by its brightness, target specificity, and duplex stability. Brightness is directly related to the conjugated label's quantum yield and extinction coefficient but also to the labeling degree, since fluorescence should, in theory, increase proportionally with the number of labels incorporated. However, high degrees of labeling can result in fluorescence quenching, a reduction of quantum yield and extinction coefficient, and also can sterically hinder probe-target duplex stability. Ultimately, fluorescent DNA probes should be optimized with regard to hybridization signal brightness.

In this work, the two-step DNA labeling method utilizing enzymatic incorporation of aa-dUTP, followed by reactive dye coupling, was optimized for single-stranded DNA (reverse transcription) and doublestranded DNA (nick translation) labeling procedures. The average number of fluorophores coupled to the DNA (DOL) was determined by absorption spectroscopy, which proved to be a convenient and reliable way of evaluating labeling efficiency. Reverse transcriptase and DNA polymerase I efficiently incorporated aa-dUTP, since the DOL of the probes correlated well with changes in aa-dUTP:dTTP ratio and yields remained constant with the concentrations of aa-dUTP used. Chemical labeling with succinimidyl ester dyes was very consistent and highly reproducible, regardless of the dye chosen. The degree of labeling achieved was dictated by the aa-dUTP:dTTP ratio and could be easily controlled to optimize the labeling procedure for hybridization signal brightness. Dot blot and FISH hybridization assays both showed the same optimal DOL, which was eight dyes per 100 bases, on average, irrespective of dye label. These probes reflect an optimal aa-dUTP:dTTP ratio of 2 : 1 for reverse transcription and 6:1 for nick translation.

The two-step labeling technique proved to be inherently consistent and versatile by virtue of the efficient incorporation of primary amines and the reliable chemical labeling reaction, which can be performed with a variety of amine-reactive dyes. The technique achieved labeling degrees much greater than the two to four dyes per 100 bases that is typically obtainable with enzymatic incorporation of dye-labeled nucleotides (3-5). Thus, the two-step labeling approach provides brighter, more sensitive hybridization probes and also facilitates multiparameter, multicolor applications. The majority of fluorophores used in this study belong to the Alexa Fluor dye series, which are highly water-soluble and photostable dyes (12), and several others have since been used with the procedure, including the Alexa Fluor 555, Alexa Fluor 568, and Alexa Fluor 647 dyes. The hydrophilic nature of these dyes is particularly advantageous for nucleic acid labeling because less hydrophilic fluorophores can destabilize probe hybridization as well as exhibit fluorescence quenching when conjugated to DNA (References 4 and 5, and Cox, unpublished data).

Fluorescence-based nucleic acid hybridization assays are ever more important in gene localization and expression studies, and high-throughput and high-density formats continue to put increasing demands on the sensitivity and utility of hybridization probes. Traditional FISH techniques utilize hapten-modified nucleotides to generate probes that are subsequently detected indirectly using antibodies or streptavidin, either fluorescently labeled or conjugated to a reporter enzyme. These approaches are not easily amenable to multicolor, multiparameter assays, are more time-consuming, and have the potential to increase background. The two-step labeling method discussed here is particularly advantageous in 
Table 3. Optimization of Double-Stranded DNA Labeling Using Chromosome $17 \alpha$-Satellite DNA Probes

\begin{tabular}{|c|c|c|c|c|c|c|c|c|c|}
\hline \multicolumn{2}{|c|}{ Dye Label } & $\begin{array}{c}\text { Alexa } \\
\text { Fluor } 350\end{array}$ & $\begin{array}{c}\text { Pacific } \\
\text { Blue }\end{array}$ & $\begin{array}{c}\text { Alexa } \\
\text { Fluor } 488\end{array}$ & $\begin{array}{c}\text { Alexa } \\
\text { Fluor } 532\end{array}$ & $\begin{array}{c}\text { Alexa } \\
\text { Fluor } 546\end{array}$ & $\begin{array}{c}\text { Alexa } \\
\text { Fluor } 594\end{array}$ & $\begin{array}{c}\text { Alexa } \\
\text { Fluor } 660\end{array}$ & $\begin{array}{c}\text { Alexa } \\
\text { Fluor } 680\end{array}$ \\
\hline ratio & aa-dUTP:dTTP & DOL & DOL & DOL & DOL & DOL & DOL & DOL & DOL \\
\hline $6: 1$ & $60 \mu \mathrm{M}: 10 \mu \mathrm{M}$ & 8.3 & 8.2 & 8.3 & 8.3 & 8.1 & 8.3 & 8.3 & 8.3 \\
\hline $3: 1$ & $30 \mu \mathrm{M}: 10 \mu \mathrm{M}$ & 7.0 & 7.0 & 7.1 & 7.1 & 6.9 & 7.1 & 7.1 & 7.1 \\
\hline $1: 3$ & $3 \mu \mathrm{M}: 10 \mu \mathrm{M}$ & 5.5 & 5.6 & 5.6 & 5.6 & 5.5 & 5.4 & 5.4 & 5.4 \\
\hline $1: 10$ & $1 \mu \mathrm{M}: 10 \mu \mathrm{M}$ & 4.5 & 4.6 & 4.5 & 4.7 & 4.5 & 4.5 & 4.5 & 4.5 \\
\hline
\end{tabular}
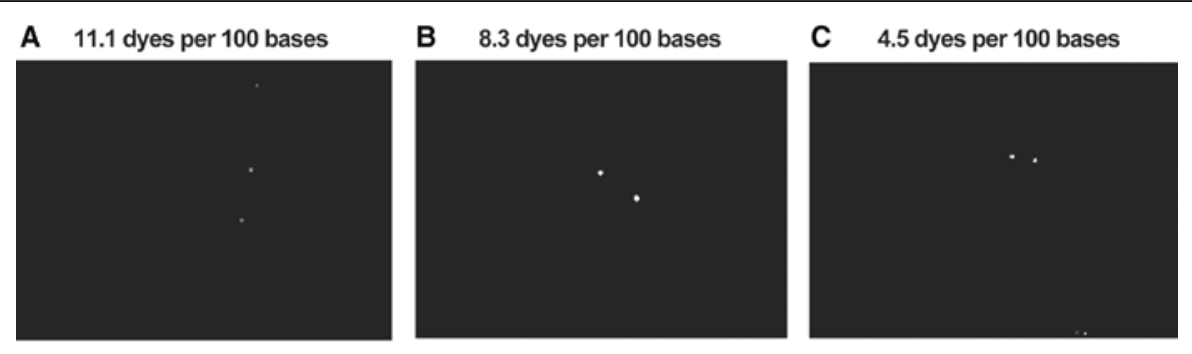

Figure 3. Fluorescence in situ hybridization (FISH) with Alexa Fluor 594 dye-labeled DNA probes. Human chromosome spreads were probed with Alexa Fluor 594 dye-labeled chromosome $17 \alpha$-satellite DNA probes. Imaging was performed on a standard fluorescence microscope with appropriate bandpass filter sets $(560 \pm 20 \mathrm{~nm}$ excitation and $635 \pm 27.5 \mathrm{~nm}$ emission) and using equivalent exposure times $(20 \mathrm{~ms})$. Shown are signals obtained from three probes labeled with Alexa Fluor 594 dye: (A) 10.2 dyes per 100 bases; (B) 8.3 dyes per 100 bases; and (C) 4.5 dyes per 100 bases.

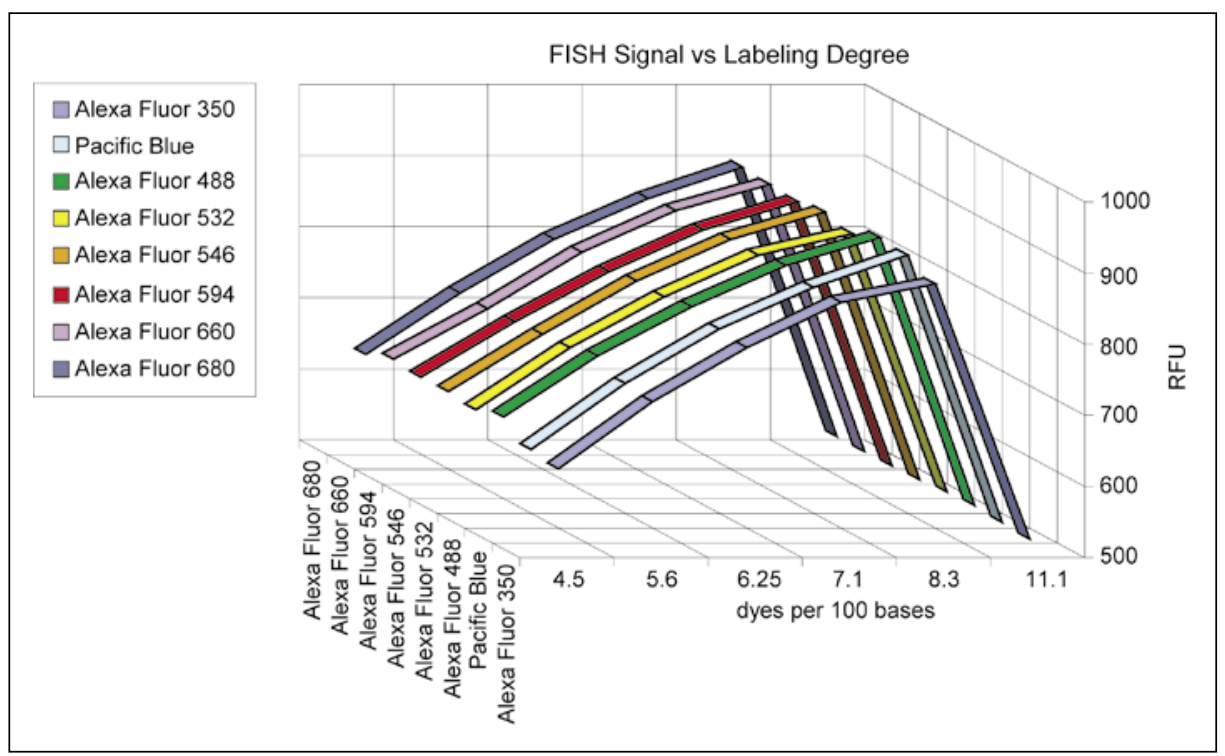

Figure 4. Image analysis of fluorescence in situ hybridization (FISH) signals. Human chromosome spreads were probed with labeled chromosome $17 \alpha$-satellite DNA probes. For each probe, 18 signals were analyzed, and the results were averaged. The standard deviation was 10-20 relative fluorescence units (RFUs). Data analysis showed that the brightest signals were obtained using probes with 6.1-8.3 dyes per 100 bases, regardless of the dye label chosen. Probes with 9.9-10.2 dyes per 100 bases always gave rise to weak signals, presumably due to poor hybridization of the excessive probe or fluorescence quenching.
FISH applications, because it is easily compatible with multicolor assays, does not require secondary detection reagents, and generates equivalently labeled probes regardless of dye label chosen. The approach has been useful for labeling DNA, as well as RNA, for FISH analysis of mitochondrial DNA localization in cultured cells, gene expression in Drosophila embryos, and single-copy DNA probes on chromosomes (Reference 15, Janes et al., unpublished data, and Cox et al., unpublished data).

The two-step labeling technique has been shown to be useful for labeling DNA and RNA for use in two-color microarray-based hybridization assays (12). Commonly, two spectrally distinct fluorescent dyes are used to label two different RNA samples, whose differences are subsequently detected by measuring the ratio of the dye signals hybridized to each gene on the array. $\mathrm{Cy} 3$ and Cy5 dyes have been instrumental in the development of microarray technology, but unequal incorporation of Cy3 and Cy5 dye-labeled nucleotides has been identified as a factor contributing to the currently accepted detection limit of twofold changes in gene expression $(8,9,16,17)$. The two-step procedure provides the production of a common pool of known amine-modified DNA appropriate for individual labelings with different fluorophores; this process allows direct comparisons of label sensitivity without 
considering varying rates of enzymatic incorporation. In fact, with probes labeled using this approach, homotypic microarray-based hybridization assays (the same RNA labeled with the two dyes and hybridized to a single array) have shown that better signal correlation coefficients are obtained with the Alexa Fluor 555 and Alexa Fluor 647 dye pair compared to the Cy3 and Cy5 dye pair (Beaudet et al., unpublished data). The two-step labeling method has also extended gene expression analyses on microarrays to three colors using Alexa Fluor 488, Alexa Fluor 546, and Alexa Fluor 594 dyes (18).

\section{ACKNOWLEDGMENTS}

We thank Matt Beaudet, Laurie Jones, Jerry Ruth, Joe Beechem, and Richard Haugland for support, useful discussions, and critical review of the manuscript, and Marci Cardon for graphics assistance.

\section{NOTE ADDED IN PROOF}

Sodium bicarbonate conjugation buffer at $0.3 \mathrm{M}$ final concentration was subsequently found to enhance labeling efficiency with certain aminereactive dyes and is now recommended for use with all amine-reactive dyes. Purification of the amine-modified DNA prior to dye conjugation can be accomplished by alcohol precipitation (1 volume of isopropanol or 2 volumes of absolute ethanol and 0.1 volume 3 $\mathrm{M}$ sodium acetate, $\mathrm{pH}$ 5.2) followed by two $70 \%$ ethanol washes, instead of by column purification. Although protein will be carried over and labeled in the labeling reaction, they will bind irreversibly to the purification column and not be eluted with the labeled nucleic acid.

\section{REFERENCES}

1.Gebeyehu, G., P.Y. Rao, P. Soochan, D.A. Simms, and L. Klevan. 1987. Novel biotinylated nucleotide-analogs for labeling and colorimetric detection of DNA. Nucleic Acids Res. 15:4513-4534.

2.Folsom, V., M.J. Hunkeler, A. Haces, and J.D. Harding. 1989. Detection of DNA targets with biotinylated and fluorescein- ated RNA probes. Effects of the extent of derivatization on detection sensitivity. Anal. Biochem. 182:309-314.

3.Holtke, H.J., R. Seibl, J. Burg, K. Muhlegger, and C. Kessler. 1990. Non-radioactive labeling and detection of nucleic acids. II. Optimization of the digoxigenin system. Biol. Chem. 371:929-938.

4.Yu, H., J. Chao, D. Patek, R. Mujumdar, S. Mujumdar, and A.S. Waggoner. 1994. Cyanine dye dUTP analogs for enzymatic labeling of DNA probes. Nucleic Acids Res. 22:3226-3232.

5.Randolph, J.B. and A.S. Waggoner. 1997. Stability, specificity and fluorescence brightness of multiply-labeled fluorescent DNA probes. Nucleic Acids Res. 25:2923-2929.

6.Zhu, Z., J. Chao, H. Yu, and A.S. Waggoner. 1994. Directly labeled DNA probes using fluorescent nucleotides with different length linkers. Nucleic Acids Res. 22:3418-3422.

7.Wiegant, J., N. Verwoerd, S. Mascheretti, M. Bolk, H.J. Tanke, and A.K. Raap. 1996. An evaluation of a new series of fluorescent dUTPs for fluorescence in situ hybridization. J. Histochem. Cytochem. 44:525-529.

8.Tseng, G.C., M.K. Oh, L. Rohlin, J.C. Liao, and W.H. Wong. 2001. Issues in cDNA microarray analysis: quality filtering, channel normalization, models of variations and assessment of gene effects. Nucleic Acids Res. 29:2549-2557.

9.Yang, Y.H., S. Dudoit, P. Lu, D.M. Lin, V. Peng, J. Ngai, and T.P. Speed. 2002. Normalization for cDNA microarray data: a robust composite method addressing single and multiple slide systematic variation. Nucleic Acids Res. 30:e15.

10.Ruth, J.L. 1983. Chemical synthesis of nonradioactively-labeled DNA hybridization probes. DNA 3:123.

11.Ruth, J.L. 1991. Oligonucleotides with reporter groups attached to the base, p. 255282. In F. Eckstein (Ed.), Oligonucleotides and Analogues: A Practical Approach. Oxford University Press, Oxford.

12.Hughes, T.R., M. Mao, A.R. Jones, J. Burchard, M.J. Marton, K.W. Shannon, S.M. Lefkowitz, M. Ziman, et al. 2001. Expression profiling using microarrays fabricated by an ink-jet oligonucleotide synthesizer. Nat. Biotechnol. 19:342-347.

13.Waye, J.S. and H.F Willard. 1986. Molecular analysis of a deletion polymorphism in alpha satellite of human chromosome 17: evidence for homologous unequal crossingover and subsequent fixation. Nucleic Acids Res. 14:6915-6926.

14.Panchuk-Voloshina, N., R.P. Haugland, J. Bishop-Stewart, M.K. Bhalgat, P.J. Millard, F. Mao, W.-Y. Leung, and R.P. Haugland. 1999. Alexa dyes, a series of new fluorescent dyes that yield exceptionally bright, photostable conjugates. J. Histochem. Cytochem. 47:1179-1188.

15.Margineantu, D.H., W.G. Cox, L. Sundell, S.W. Sherwood, J.M. Beechem, and R.A. Capaldi. 2002. Cell cycle dependent morphology changes and associated mitochondrial DNA redistribution in mitochondria of human cell lines. Mitochondrion 1:425-435.

16.Schena, M., D. Shalon, R.W. Davis, and
P.O. Brown. 1995. Quantitative monitoring of gene expression patterns with a complementary DNA microarray. Science 270 : 467-470.

17.Schena, M., D. Shalon, R. Heller, A. Chai, P.O. Brown, and R.W. Davis. 1996. Parallel human genome analysis: microarray-based expression monitoring of 1000 genes. Proc. Natl. Acad. Sci. USA 93:10614-10619.

18.Schut, G.J., J. Zhou, and M.W.W. Adams. 2001. DNA microarray analysis of the hyperthermophilic archaeon pyrococcus furiosus: evidence for a new type of sulfur-reducing enzyme complex. J. Bacteriol. 183:7027-7036.

Received 21 July 2003; accepted 27 October 2003.

Address correspondence to:

W. Gregory Cox

Molecular Probes, Inc.

29851 Willow Creek Road

Eugene, OR 97402, USA

e-mail: Greg.cox@probes.com 